\title{
Modeling the toxicity of dissolved crude oil exposures to characterize the sensitivity of cod (Gadus morhua) larvae and role of individual and unresolved hydrocarbons
}

\author{
Bjørn Henrik Hansen ${ }^{\mathrm{a}, *}$, Thomas Parkerton ${ }^{\mathrm{b}}$, Trond Nordtug ${ }^{\mathrm{a}}$, Trond R. Størseth ${ }^{\mathrm{a}}$, Aaron Redman ${ }^{\mathrm{c}}$ \\ ${ }^{a}$ SINTEF Ocean AS, Environment and New Resources, Trondheim, Norway \\ ${ }^{\mathrm{b}}$ ExxonMobil Biomedical Sciences, Spring, TX, USA \\ ${ }^{\mathrm{c}}$ ExxonMobil Petroleum and Chemical, Machelen, Belgium
}

A R T I C L E I N F O

\section{Keywords:}

Atlantic cod

Weathered crude oil

Toxicity

Droplets

Target lipid model

Toxic units

\begin{abstract}
A B S T R A C T
Toxicity of weathered oil was investigated using Atlantic cod (Gadus morhua) larvae. A novel exposure system was applied to differentiate effects associated with dissolved and droplet oil with and without dispersant. After a 4-day exposure and subsequent 4-day recovery period, survival and growth were determined. Analytical data characterizing test oil composition included polyaromatic hydrocarbons (PAH) based on GC/MS and unresolved hydrocarbon classes obtained by two-dimensional chromatography coupled with flame ionization detection was used as input to an oil solubility model to calculate toxic units (TUs) of dissolved PAHs and whole oil, respectively. Critical target lipid body burdens derived from modeling characterizing the sensitivity of effect endpoints investigated were consistent across treatments and within the range previously reported for pelagic species. Individually measured PAHs captured only $3-11 \%$ of the TUs associated with the whole oil highlighting the limitations of traditional total PAH exposure metrics for expressing oil toxicity data.
\end{abstract}

\section{Introduction}

Past oil spill research has largely focused on the fate of surface spills and effects on shorelines and pelagic and nektonic species. However, following the Deepwater Horizon tragedy, increased attention has been directed to deep sea oil releases (Murphy et al., 2016). While systems for incident prevention serve as the principal defense to avoid such spills, a key strategy for mitigating the safety and environmental impacts associated with a subsea well release of oil is use of subsea dispersants (John et al., 2016). When applied subsea, dispersants reduce the size of oil droplets, increasing the dissolution rate and reducing the droplet rise velocity thereby increasing the residence time for degradation in the water column, and limiting formation of oil slicks and oiled shorelines (Johansen et al., 2013; Prince, 2015). However, an important risk trade-off when applying subsea dispersants is the increase in oil exposure to the deep ocean environment (NRC, 2005). Thus, understanding the relative sensitivity of deep sea species to dispersed oil is a current research priority for response decision-making (DeLeo et al., 2016).

Atlantic cod (Gadus morhua) inhabit the deeper, colder regions of the Northern Atlantic Ocean. Adults are usually found in deeper waters at depths up to $600 \mathrm{~m}$, while embryos and larvae reside in coastal pelagic environments and juveniles prefer sublittoral waters (Froese and Pauly, 2017). This species has been one of the commercially most important fish species in the Northern Hemisphere for centuries (Ottera, 2004). Currently this species is labelled vulnerable on the IUCN Red List of Threatened Species, a likely result of overfishing (Sobel, 1996), although promising signs of population recovery of western population stocks have recently been reported (Rose and Rowe, 2015). Atlantic cod engages in diel vertical migrations off the sea bottom and into the water column at night to prey on invertebrates and fish (Froese and Pauly, 2017). The commercial relevance recognized vulnerability and barotolerance, which facilitates field collection and laboratory testing under ambient pressure, provide the rationale for investigating the sensitivity of this species to oil exposures.

Several studies have investigated the effects of dispersed oil on this species. In a screening study by Khan and Payne (2005), mortality of adult Atlantic cod and three other mature fish species were investigated following a single 4 day declining exposure to Hibernia crude oil with and without dispersant (1:1 dispersant to oil ratio (DOR)). Cod tended to be among the most sensitive of the fish species investigated. At the nominal loading of $0.25 \mathrm{~mL} / \mathrm{L}$ for the dispersant or oil alone, reported

\footnotetext{
* Corresponding author at: SINTEF Ocean AS, Environment and New Resources, Postboks 4762 Torgarden, 7465 Trondheim, Norway.

E-mail address: bjorn.h.hansen@sintef.no (B.H. Hansen).
} 
mortality was $53 \%$ and $40 \%$, respectively. For the dispersed oil wateraccommodated fraction (WAF) prepared at the same nominal loading with both dispersant and oil (i.e. total loading of $0.5 \mathrm{~mL} / \mathrm{L}$ ) mortality increased to $70 \%$. This observed toxicity is consistent with predictions assuming dispersant and oil act independently.

Nordtug et al. (Nordtug et al., 2011a, 2011b) applied a continuous dosing system to expose Atlantic cod larvae to five concentrations of artificially weathered Troll crude oil dispersions with uniform size distributions for 4 days followed by 4 day recovery period in clean seawater. Oil-dosed seawater was then delivered directly or first filtered through glass wool to exposure chambers so comparative effects of dissolved plus droplet oil versus dissolved oil could be inferred. Results indicated that food assimilation rate and survival likely decreased in a concentration-dependent manner with reported median effect concentrations (EC50s) of 2 and $40 \mu \mathrm{g} / \mathrm{L}$, respectively, based on the sum of parent and alkylated PAHs and analyzed using gas chromatography-mass spectrometry (GC/MS). No consistent differences were found between the unfiltered and filtered treatments indicating oil droplets did not modulate toxicity. In a follow-up study, larval gene expression was not significantly altered by the presence of oil droplets (Olsvik et al., 2011). In a different experiment, cod larvae were exposed to dispersions of chemically and mechanically dispersed Troll Oil of similar droplet size at three nominal oil concentrations $(0.25,0.79$, or $2.5 \mathrm{mg}$ oil/L) for 4 days (Hansen et al., 2016). Total PAH concentrations determined by GC/MS in the highest mechanically and chemically dispersed treatments were 8.7 and $8.4 \mu \mathrm{g} / \mathrm{L}$, respectively. Approximately $50 \%$ of larvae (at first feeding stage) exposed to these concentrations survived and comparable survival was observed for larvae subjected to food deprivation alone. A significant concentration-dependent reduction in dry weight was noted for oil exposures compared to controls. The results of Hansen et al. (2016) and Nordtug et al. (2011b) suggest that dissolved oil exposures may reduce survival and growth due to inadequate nutrition from impaired larval feeding.

The above studies indicate that oil droplets serve a limited role in contributing to cod larvae toxicity and are consistent with earlier work (Carls et al., 2008; Redman et al., 2016). Available data also support the generalization that dispersants can enhance oil bioavailability (i.e., dissolved hydrocarbons), as reported in previous studies (Couillard et al., 2005; Mu et al., 2014; Ramachandran et al., 2004; Schein et al., 2009; Van Scoy et al., 2012; Wu et al., 2012). However, given the different test oils, dosing and analysis methods, exposure metrics, life stages and effect endpoints, comparison of toxicity results across the different studies summarized above is impossible. Further, it is unclear how sensitive Atlantic cod are to crude oil exposures relative to other test species. A model that predicts the concentration and composition of dissolved oil exposures can facilitate analysis and interpretation of such datasets by combining improved assessment of test exposures with observed dose response relationships.

The PETROTOX model was developed to predict the aquatic toxicity of petroleum substances for a given organism/effect endpoint based on oil composition and test-specific design considerations (Redman et al., 2012b). Composition is determined by analysis of the component masses of different hydrocarbon classes and carbon numbers that comprise the test oil using two-dimensional gas chromatography coupled to flame ionization detection (2d-GC). Based on the physiochemical properties of a library of hydrocarbons with representative structures that are mapped to these components, the test specific oil dissolution is simulated in the dosing system used to assess toxicity. A key advantage of this approach is that a more complete compositional characterization of dissolved oil can be simulated than traditional analysis which quantitates only a subset of hydrocarbons present in the oil (e.g., benzene, toluene, ethylbenzene and xylenes [BTEX], targeted parent and alkylated PAHs) and fails to differentiate dissolved from droplet oil phases (Redman, 2015). The dissolved component concentrations calculated by PETROTOX are normalized by the predicted toxicity of each component to compute toxic units (TUs). Assuming toxicity of the components can be described using concentration addition, the TUs for each component are then summed as a preferred exposure metric for evaluating concentration-response relationships and predicting toxicity for a given organism/endpoint (Redman and Parkerton, 2015). The toxicity of the individual components is estimated using the Target Lipid Model (TLM) and hydrocarbon classspecific adjustment factors (McGrath and Di Toro, 2009). The TLM is based on an organism-specific critical target lipid body burden (CTLBB) and estimated component partition coefficients to target lipid, which is estimated from the Log octanol-water partition coefficient (Log Kow). Organism specific CTLBBs for a defined endpoint are estimated by fitting the TLM to toxicity datasets for individual hydrocarbons or related substances. A compilation of CTLBBs for both acute and chronic in-vivo endpoints across different aquatic species is provided by McGrath et al. (2018). The utility of using TUs (derived using this approach) to successfully describe toxicity of different oils and dosing methods across species has been demonstrated (Kang et al., 2014; Redman et al., 2016; Redman et al., 2014). However, based on a recent review by Klok et al. (2014), toxicity data for Atlantic cod on individual hydrocarbons are not available to derive endpoint-specific CTLBBs for this species.

The main objective of this study is to illustrate an alternative approach using the TU concept for deriving Atlantic cod survival and growth CTLBB estimates based on analysis of empirical toxicity data for dispersed crude oil with and without dispersant. The estimated CTLBBs from this analysis are then compared to CLTBBs reported for other species to determine the relative sensitivity of this species to oil. A secondary goal is to determine the extent to which the subset of PAHs that were quantified in the aqueous test media understates the TUs associated with the unresolved components of the whole test oil and identify what unresolved oil components are predicted to be the most important contributors to adverse effects. The potential opportunities and advantages of extending this strategy in analyzing and interpreting additional toxicity studies with different oils and test species are also discussed.

\section{Materials and methods}

\subsection{Test oil}

A naphthenic crude oil (Troll) from the North Sea was obtained. The oil was weathered in a one-distillation step at $200{ }^{\circ} \mathrm{C}$ (Stiver and Mackay, 1984), and the residue was used for the experiments. This weathering process removes a substantial amount of the most volatile, but also water-soluble and biodegradable, components, including BTEXs. This oil and weathering degree have been used in a series of previous experiments where detailed compositional analyses were available. Two-dimensional chromatography coupled with flame ionization detection (2d-GG) was used to characterize the mass distribution of the hydrocarbon classes that comprise the test oil as a function of carbon number. Detailed analysis of individual 2-5 ring PAHs in the oil was also performed by GC/MS operated in selected ion monitoring (SIM) mode.

\subsection{Preparation of exposure solutions}

The full description and validation of the experimental set-up has been previously reported by Nordtug et al. (2011a), and has been used for toxicity experiments with early life stages of fish (Hansen et al., 2016; Nordtug et al., 2011b; Olsvik et al., 2011; Olsvik et al., 2012; Olsvik et al., 2010). Briefly, the weathered test oil [with chemical dispersant (CD) or without (MD)] was dispersed into filtered $(5 \mu \mathrm{m}$ pore diameter) seawater through a series of nozzles yielding a constant flow of dispersion with homogenous droplet size. The objective of the exposure system is to directly compare the effects of test solutions with and without the presence of oil droplets. A dilution series is created from the original dispersion and the water-soluble fraction (WSF) of 
each dilution is separated from particulate oil by filtration. Thus, the experiment consisted of two parallel exposure series, one with diluted dispersion (unfiltered) and one with the corresponding WSF (filtered). The concentration gradient used for the dispersion was logarithmic with a spacing of 0.5 log-units between concentrations. The filter units consisted of fine glass wool on top of a Whatman glass fiber filter. The exposure containers consisted of $5 \mathrm{~L}$ Schott borosilicate glass bottles (Schott AG) with their base removed and placed upside down in a water bath. Exposure solutions and natural seawater (controls) were added in the lower part of the exposure container through Teflon tubing (bore $1 \mathrm{~mm}$ ). Water was drained from the surface through a $300 \mu \mathrm{m}$ plankton mesh.

A peristaltic pump (Watson-Marlow) equipped with Marphrene ${ }^{\circledR}$ tubing was used to draw the dispersion through the glass filters and into the WSF exposure containers. Dispersions were added passively to the exposure containers through inlet Teflon resistance tubes with an inner diameter of $1 \mathrm{~mm}$ and flow was adjusted by the height of the inlet water column. Three identical exposure systems were used to achieve three biological replicates for every exposure concentration. To characterize actual exposure concentrations in unfiltered and filtered treatments samples were collected and analyzed for a suite of PAHs that were quantified in the test oil.

\subsection{Larval toxicity tests}

In May 2009, a test was performed without dispersant (mechanically dispersed oil, MD). In November 2009, a second test was performed, but this test included dispersant (Dasic Slickgone NS, Dasic international Ltd.) and the dispersant was premixed into the oil at a dispersant to oil ratio (DOR) of 1:25 (chemically dispersed oil, CD). The tests were run in sequence rather than in parallel due to logistic and resource constraints. A dispersant only treatment was not included since at the oil concentrations applied (see below), the dispersant would be present at $\leq 0.1 \mathrm{mg} / \mathrm{L}$ which is well below concentrations posing toxicity concerns (Hansen et al., 2014). To maintain similar mixing conditions in the two experiments, the energy introduced during the creation of the droplets was limited by reducing the water flow through the dispersion generator. This caused the mean volumetric droplet size distributions in the two experiments as recorded by a Coulter Counter Multisizer (Beckman Inc.) to be approximately similar at 12.8 ( \pm 0.12 , standard deviation) and $10.4( \pm 0.11) \mu \mathrm{m}$ for the dispersions generated without and with dispersant, respectively.

Fertilized cod eggs (Gadus morhua; Marine Harvest Cod, Norway) were transported to the SINTEF Sealab laboratory, where they hatched, and the larvae were maintained. At 9 days post hatch (dph), cod larvae were exposed to five different nominal concentrations of dispersions (25-2500 $\mu \mathrm{g}$ oil/L) and corresponding filtered dispersions, i.e., WSFs until $13 \mathrm{dph}$. At $13 \mathrm{dph}$, a four-day recovery period started in clean sea water until the experiment ended at $17 \mathrm{dph}$. All treatments were done in triplicates, except the control treatment, which consisted of 12 replicates. The approximate initial number of larvae per replicate was 240. During the experiment, the larvae were fed rotifers in green water (Isochrysis galbana). Dead larvae were removed and counted daily during the whole period whereas dry weights were measured in subsampled larvae (12 from each tank/replicate) at the start ( $9 \mathrm{dph})$ and end of exposure ( $13 \mathrm{dph}$ ), and after the recovery period ( $17 \mathrm{dph})$. The experiment was conducted with natural seawater collected at $70 \mathrm{~m}$ depth in the Trondheim Fjord. The water was sand filtered, matured for approximately $24 \mathrm{~h}$ and temperature adjusted in heat exchangers before being equilibrated with oxygen. The acclimated seawater was then filtered by a $2 \mu \mathrm{m}$ in-line cartridge filter (Cuno). The salinity was approximately $35.5 \mathrm{ppt}$ and the oxygen saturation in the exposure containers was between 95 and $98 \%$ throughout the experiments. The experiments were conducted under constant temperature $\left(12 \pm 1{ }^{\circ} \mathrm{C}\right)$ and dim light conditions with individual light-emitting diodes (LEDs) illuminating a diffusing cover on top of each exposure container.

\subsection{Chemical analyses using GC-MS}

Water samples for chemical analysis (approximately $900 \mathrm{~mL}$ each) were collected one and three days into the exposure period from all exposures and groups. The water samples were acidified (to $\mathrm{pH}<2$ ) with diluted hydrochloric acid, extracted with dichloromethane, dried over $\mathrm{Na}_{2} \mathrm{SO}_{4}$ and concentrated to $1 \mathrm{~mL}$. Analysis for the same suite of 44 PAHs (see target list in Table S2) measured in the oil were also targeted in water samples using GC/MS-SIM. The system comprised of a HP6890N gas chromatograph fitted with a Hewlett- Packard HP7683B Series auto-sampler and a HP5975B quadrupole mass selective detector. The column was a Phenomenex ZB-5MS fused silica capillary column ( $30 \mathrm{~m} \times 0.25 \mathrm{~mm}$ id $\times 0.25 \mathrm{~mm}$ film thickness). The carrier gas was helium at a constant flow of $1.0 \mathrm{~mL} / \mathrm{min}$. A $1.0 \mu \mathrm{L}$ sample was injected into a $310^{\circ} \mathrm{C}$ splitless injector. The oven temperature was programmed from $40^{\circ} \mathrm{C}$ for $1 \mathrm{~min}$, then to $315^{\circ} \mathrm{C}$ at $6{ }^{\circ} \mathrm{C} / \mathrm{min}$ and held for $15 \mathrm{~min}$. Data and chromatograms were monitored and recorded using MSD ChemStation (version D.03.00.611) software. The quadrupole mass spectrometer ion source temperature was $230^{\circ} \mathrm{C}$. The exposure concentrations were stable over time and concentrations for each PAH were reported as the mean value of results obtained on day 1 and day 3 of the exposure period.

\subsection{Statistical analysis}

To compare survival and dry weights of larvae between controls and exposed larvae and between parallel filtered and unfiltered treatments, one-way ANOVA followed by Dunnett's multiple comparisons test was performed using GraphPad Prism version 6.00 for Windows, GraphPad Software, La Jolla California USA, www.graphpad.com. Traditional dose response analysis of oil toxicity data was performed by evaluating observed effects on cod larvae survival and growth as a function of measured total PAH concentrations in MD and CD unfiltered and filtered treatments. Lethal concentrations (LC50s) and effect concentrations (EC20s) for growth impairment were computed with Non-linear fit (variable slope, four parameters) using GraphPad Prism.

\subsection{Modeling dissolved hydrocarbon exposures and toxic units}

The modeling analysis applied in this study is outlined in Fig. 1 and involved application of two models to predict the dissolved oil concentrations and associated toxic units of the a) targeted list of PAHs that were quantified using GC-MS and b) the whole oil as represented by $2 \mathrm{~d}$ GC composition. In the first analysis, PAH concentrations (Table S2) in the oil were used as inputs into an oil solubility model (Redman et al., 2012a) to predict dissolved concentrations of PAH components in each filtered treatment (where it is assumed droplet oil was excluded). The model simulates the distribution of PAHs between three phases (oilwater-air) based on the principles of mass conservation and equilibrium partitioning using Raoult's and Henry's Laws and is available as a spreadsheet tool (Redman and Parkerton, 2015). This model was run iteratively to determine the oil loading that successfully fit mean measured concentrations of individual PAHs determined in the filtered water samples. In step 2, the estimated oil loading from step 1 was used as input into the solubility model to match mean concentrations of individual PAHs observed in collected water samples from the unfiltered treatment where droplets were present. This step involved iteratively selecting droplet oil concentrations that minimized differences between predicted and measured PAH concentrations in each unfiltered treatment. This analysis assumes that oil and water are at equilibrium, so droplet size does not alter the predicted dissolved exposures which are the same in filtered and unfiltered exposure systems.

In the second analysis, oil composition based on 2d-GC analysis (Table S1) and estimated oil loadings derived in Step 1 can be input to the PETROTOX model (Redman et al., 2012b). This model is freely available at https://www.concawe.eu/reach/petrotox/ and includes a 


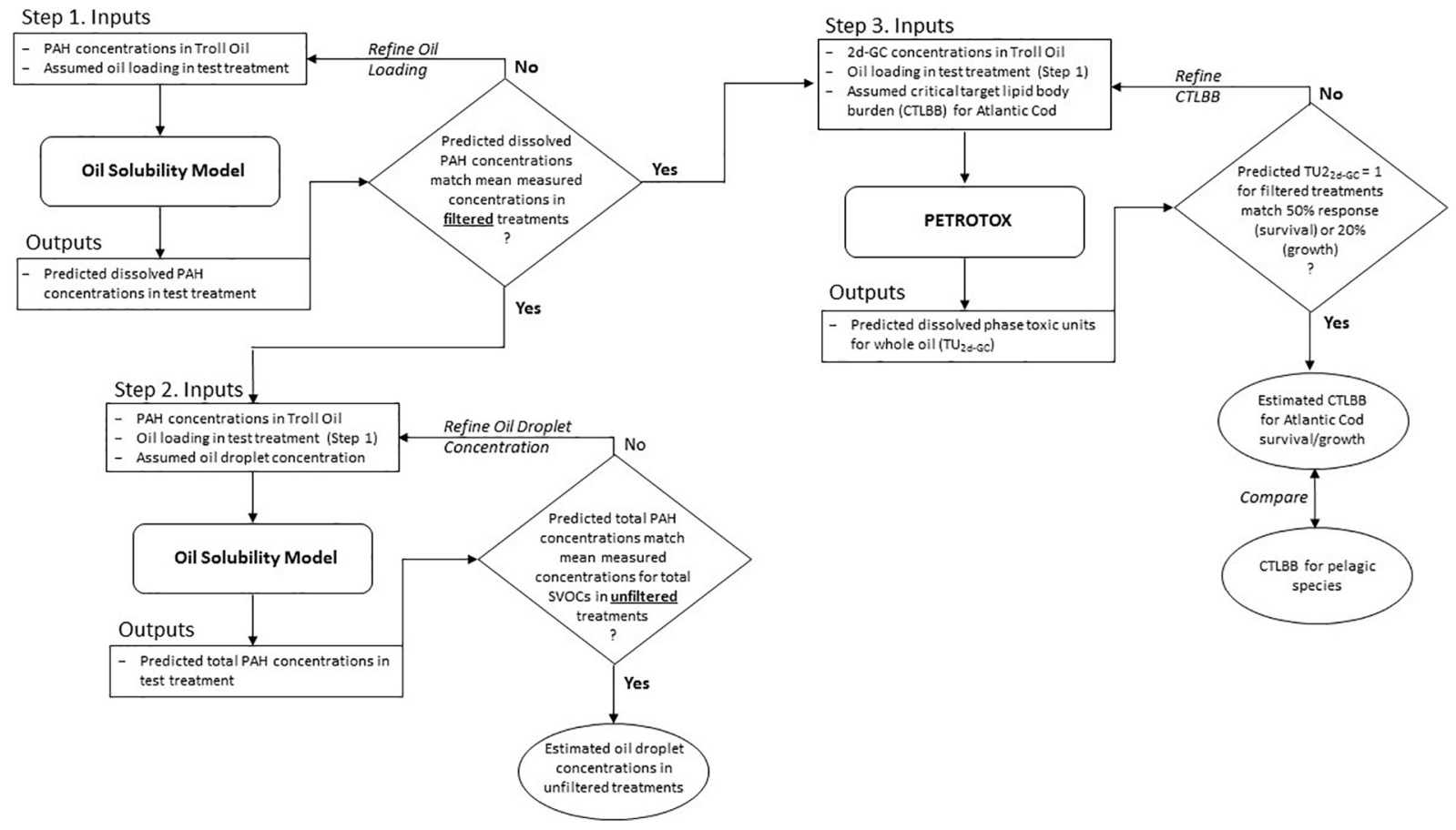

Fig. 1. Flow chart describing modeling framework used in the analysis of oil toxicity test data.

user guide that provides further details on use. To compute test exposures in terms of dissolved whole oil toxic units (TUs) in both MD and CD treatments, the CTLBB for the specific organism/effect endpoint is a required input. However, in the case of Atlantic cod, a CTLBB is not available. Thus, in step 3 we used the PETROTOX model to estimate the CTLBB for survival such that the observed TU-response relationship fitted using log-logistic regression exhibited $50 \%$ cod larvae mortality at a predicted dissolved acute $\mathrm{TU}=1$. The acute CTLBB derived from this analysis was then compared to CTLBBs reported for various pelagic species to gain insights on the relative sensitivity of this deep-sea species to oil exposure. A similar analysis was repeated to determine a chronic CTLBB for which a $20 \%$ effect on cod larval growth corresponded to a predicted dissolved TU $=1$. Given the estimated CTLBBs, the $\Sigma$ TUs associated with the dissolved exposures for the resolved PAHs at each loading from Step 1 was also calculated for comparison to the $\Sigma$ TUs for the whole oil derived from the 2d-GC composition in Step 3. This analysis allows the contributing role of resolved PAHs to toxicity to be quantified relative to that of the unresolved components that comprise the whole oil. Modeling in step 3 also provides insights on the importance of different unresolved hydrocarbon classes in accounting for predicted oil toxicity. All model simulations used a headspace of $25 \%$.

\section{Results and discussion}

\subsection{Characterization of the test oil}

Detailed 2d-GC analytical characterization data are provided in Table S1 and indicated that the test oil was comprised of $11 \%$ normal and isoparaffins, $45 \%$ naphthenics (i.e., cycloalkanes), and $26 \%$ aromatic hydrocarbon classes with carbon numbers up to C30 with the remaining $18 \%$ representing a residual fraction of higher carbon number components. This latter fraction is assumed not to contribute to aquatic toxicity (Redman et al., 2012b). Concentrations of the 44 resolved PAHs determined using GC-MS are provided in Table S2, which collectively amounted to concentration of $16.4 \mathrm{~g} / \mathrm{kg}$ oil or $1.64 \%$ of the oil mass.

\subsection{Characterization and modeling of exposure solutions}

Individual analyte and total PAH measurements for the MD and CD experiments are summarized in Tables S3 and S4, respectively. For the MD experiment without dispersant, total mean measured PAH concentrations in unfiltered treatments ranged from 0.1 to $28.8 \mu \mathrm{g} / \mathrm{L}$ whereas filtered treatments ranged from 0.2 to $15.1 \mu \mathrm{g} / \mathrm{L}$. In the case of the $\mathrm{CD}$ experiment with dispersant, total measured concentrations in unfiltered and filtered treatments ranged from 0.05 to 27.9 and 0.07 to $12.5 \mu \mathrm{g} / \mathrm{L}$, respectively. Thus, similar total dispersed and filtered PAH exposures were achieved in these separate tests.

Oil concentrations of PAHs (Table S2) were used as input to the oil solubility model to estimate oil loadings and droplet oil concentrations that matched observed PAH concentrations in filtered and unfiltered treatments (Fig. 1). Table 1 summarizes the estimated oil loadings and droplet concentrations for each test treatment based on this modeling analysis. Results indicate that estimated oil loading corresponding to the observed measured PAH concentrations in filtered treatments range from 5 to $1500 \mu \mathrm{g} / \mathrm{L}$. In the case of the CD test, the loadings derived by fitting the filtered treatments at the two highest exposures are slightly less than the oil droplet concentrations obtained by fitting the total measured concentrations in the corresponding unfiltered treatments. This suggests some losses may have occurred during the filtration step. The results of the calibration procedure for the highest treatment exposure are illustrated in Fig. 2, while further plots are provided for the lower test exposures in Fig. S1. Predicted concentrations of individual PAHs for unfiltered WAFs appear to fall on the 1:1 line (left hand panels in Fig. 2) for both MD and CD experiments. Predicted concentrations are in generally good agreement with measured concentrations in filtered treatments particularly for the more soluble components, but predictions tend to be higher than measured concentrations for the poorly soluble components that are likely more susceptible to losses during the filtration process and toxicity test exposures.

It should be pointed out that using the dosing system applied in this study, equilibrium conditions are assumed and appear to be reasonably described using the solubility model applied. However, during oil spills in the field where rapid dilution of droplet oil occurs over short time scales dissolution may be kinetically limited by mass transfer 
Table 1

Summary of modeling results for each exposure treatment.

\begin{tabular}{|c|c|c|c|c|c|c|c|c|}
\hline Test & Treatment & $\begin{array}{l}\text { Estimated } \\
\text { Oil Loading }(\mu \mathrm{g} / \mathrm{L})\end{array}$ & $\begin{array}{l}\text { Predicted } \\
\text { Oil Droplet }(\mu \mathrm{g} / \mathrm{L})\end{array}$ & $\begin{array}{l}\text { Total Predicted } \\
\text { TPAH }(\mu \mathrm{g} / \mathrm{L})\end{array}$ & $\begin{array}{l}\text { Total Measured } \\
\text { TPAH }(\mu \mathrm{g} / \mathrm{L})\end{array}$ & $\begin{array}{l}\text { Acute } \\
\text { TUs from } \\
2 d-G C\end{array}$ & $\begin{array}{l}\text { Acute } \\
\text { TUs from } \\
\text { TPAH }\end{array}$ & $\begin{array}{l}\text { ТPAH } \\
\text { contribution to Acute TUs (\%) }\end{array}$ \\
\hline \multirow[t]{10}{*}{ MD } & D1 & 10 & 0 & 0.2 & 0.1 & 0.08 & 0.003 & 3.3 \\
\hline & D2 & 50 & 0 & 1.0 & 1.0 & 0.25 & 0.012 & 4.6 \\
\hline & D3 & 150 & 0 & 3.0 & 2.5 & 0.47 & 0.030 & 6.4 \\
\hline & D4 & 500 & 150 & 10.6 & 9.2 & 0.89 & 0.073 & 8.2 \\
\hline & D5 & 1500 & 1000 & 36.0 & 28.8 & 1.37 & 0.144 & 10.5 \\
\hline & $\mathrm{F} 1$ & 10 & 0 & 0.2 & 0.2 & 0.08 & 0.003 & \\
\hline & $\mathrm{F} 2$ & 50 & 0 & 1.0 & 0.9 & 0.25 & 0.012 & \\
\hline & F3 & 150 & 0 & 2.9 & 1.9 & 0.47 & 0.030 & \\
\hline & F4 & 500 & 0 & 8.3 & 6.1 & 0.89 & 0.073 & \\
\hline & F5 & 1500 & 0 & 20.1 & 15.1 & 1.37 & 0.144 & \\
\hline \multirow[t]{10}{*}{$\mathrm{CD}$} & D1 & 5 & 0 & 0.1 & 0.05 & 0.05 & 0.001 & 2.9 \\
\hline & D2 & 15 & 1 & 0.3 & 0.3 & 0.11 & 0.004 & 3.8 \\
\hline & D3 & 70 & 13 & 1.6 & 1.1 & 0.31 & 0.016 & 5.2 \\
\hline & D4 & 200 & 272 & 8.2 & 8.3 & 0.57 & 0.038 & 6.6 \\
\hline & D5 & 1000 & 1237 & 34.9 & 27.9 & 1.19 & 0.114 & 9.7 \\
\hline & $\mathrm{F} 1$ & 5 & 0 & 0.1 & 0.07 & 0.05 & 0.001 & \\
\hline & $\mathrm{F} 2$ & 15 & 0 & 0.3 & 0.3 & 0.11 & 0.004 & \\
\hline & F3 & 70 & 0 & 1.4 & 1.0 & 0.31 & 0.016 & \\
\hline & F4 & 200 & 0 & 3.7 & 4.4 & 0.57 & 0.038 & \\
\hline & F5 & 1000 & 0 & 14.6 & 12.5 & 1.19 & 0.114 & \\
\hline
\end{tabular}

$\mathrm{D}=$ dispersed (unfiltered); $\mathrm{F}=$ filtered; $\mathrm{TPAH}=$ total polyaromatic hydrocarbons; $\mathrm{TUs}=$ toxic units.

considerations thereby precluding equilibrium conditions. Thus, the experimental design used in this study provides a conservative basis for evaluating oil exposure and should not be directly extrapolated to infer effects in the field where disequilibrium and weathering processes can alter both the concentration and composition of dissolved oil exposures.

\subsection{Toxicity results}

Larval cod survival and growth data for both tests are summarized in Table 2. Control survival in CD and MD test were $89.8 \pm 4.3$ and $83.8 \pm 7.5 \%(\mathrm{~N}=12)$, which reflects acceptable survival for lab
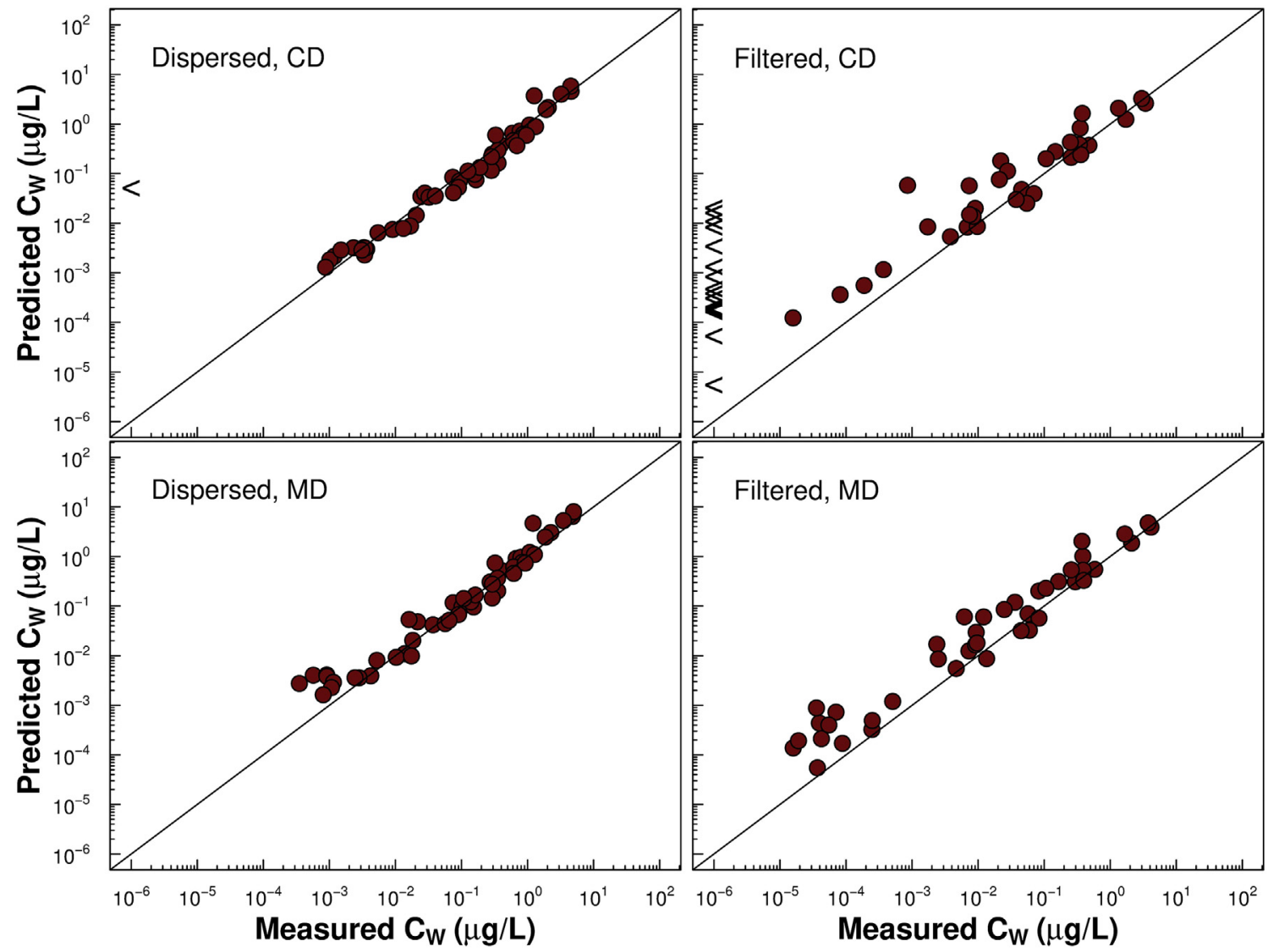

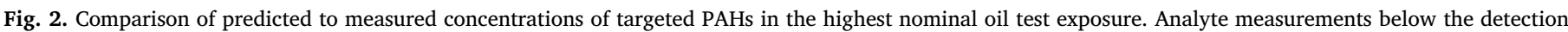

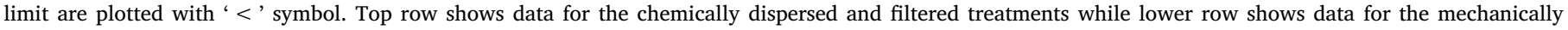
dispersed and filtered treatments. 
toxicity tests. Larval weights for controls were $0.29 \pm 0.05 \mathrm{mg}$ dry $(\mathrm{N}=144)$ and $0.17 \pm 0.05 \mathrm{mg}$ dry $(\mathrm{N}=142)$ in the MD and CD experiments, respectively. The weight difference between the two groups may be related to the fact that stock fish used to produce the eggs from the $\mathrm{CD}$ test were light manipulated to spawn in the autumn, whereas the eggs from the MD test were obtained after a slightly delayed natural spawning. Since the egg batch that produced the smaller larvae used in the CD treatment had slightly better mean control survival, larvae were judged healthy despite the smaller size.

Statistically significant reductions in survival were observed only at the highest oil exposures for the CD test and at the two highest exposures in the MD test. Differences in observed survival between parallel filtered and un-filtered treatments were not significant for the MD treatment, and significant only for the highest exposure in the CD treatment (D5 vs. W5, p < 0.01). Growth reductions were slightly more pronounced after the 4-d recovery period than at the end of test exposure (data not shown). Detectable effects on growth relative to the controls were observed after $17 \mathrm{dph}$ for the MD exposure in the D2 (p $<0.0001)$, D3 (p $<0.001)$, D4 (p $<0.001)$, F3 (p $<0.01)$, F4 $(\mathrm{p}<0.0001)$ and F5 (p $<0.0001)$ and for the CD exposure in the D2 ( $\mathrm{p}<0.01)$, D4 ( $<<0.0001)$, D5 ( $\mathrm{p}<0.0001)$, F4 ( $<<0.0001)$ and F5 ( $\mathrm{p}<0.0001)$ treatments. Comparing parallel filtered and un-filtered treatments, significant differences were only observed between the D2 and F2 treatments $(\mathrm{p}<0.01)$ for the MD exposure, and for none of the parallel CD treatments. These results indicate that dissolved phase oil primarily dictates observed toxicity on either survival or growth of cod larvae, not dispersant nor droplet oil, consistent with earlier studies (Carls et al., 2008; Gardiner et al., 2013; Nordtug et al., 2011b; Olsvik et al., 2011; Olsvik et al., 2010).

Predicted 4-d $\mathrm{LC}_{50}$ values and $\mathrm{EC}_{50}$ estimates for larval growth inhibition following 4-d exposure and a subsequent 4-d recovery period in clean water using total PAH measurements (Table 1) as the exposure metric are reported in Table 3. Results indicate mechanically dispersed oil exhibits LC50s that are about 3-fold lower than chemically dispersed oil. For sublethal effects on larval growth estimated EC50s are more uncertain, but are generally comparable between MD and CD treatments.

\subsection{Estimating CTLBB from observed toxicity and predicted TUs for the whole oil}

Dissolved oil exposures derived using the 2d-GC compositional input were combined with the estimated oil loadings provided in Table 1 to calculate dissolved TUs for different CTLBB values. This calculation was performed iteratively across all treatments in both experiments to determine a CTLBB estimate corresponding to a $50 \%$ acute response at $\mathrm{TU}=1$ as illustrated in Fig. $3 \mathrm{~A}$. This procedure yielded an acute $4 \mathrm{~d}$ CTLBB estimate for Atlantic Cod of $42 \mu \mathrm{mol} / \mathrm{g}$ octanol, which falls within the range reported for other pelagic species ( 9 to $327 \mu \mathrm{mol}$ / $\mathrm{g}$ octanol, $\mathrm{N}=79$ species) based on acute effect endpoints for single hydrocarbons (McGrath et al., 2018). This value is a factor of two lower than the CTLBB of $81 \mu \mathrm{mol} / \mathrm{g}$ octanol derived from 5-d zebrafish

Table 3

Toxicity (LC50) of dispersed Troll Oil on cod larvae survival after exposure (d 13) relative to control, and growth (increase in DW relative to newly hatched larvae) after 4 days recovery (d 17) based on measured total PAH exposures.

\begin{tabular}{lcc}
\hline Experiment & $\mathrm{LC}_{50}(\mu \mathrm{g} / \mathrm{L})$ & $\mathrm{EC}_{50}(\mu \mathrm{g} / \mathrm{L})$ \\
\hline MD unfiltered & $9(7-12)$ & $5(2-12)$ \\
MD filtered & $6(4-8)$ & $6(3-14)$ \\
CD unfiltered & $38^{\mathrm{a}}(31-45)$ & $8(2-30)$ \\
CD filtered & $26(21-30)$ & $11(\mathrm{CNC})$ \\
\hline
\end{tabular}

$\mathrm{MD}=$ mechanically dispersed; $\mathrm{CD}=$ chemically dispersed; $\mathrm{CNC}=$ could not calculate reliable confidence intervals.

${ }^{\mathrm{a}}$ Extrapolated values. 

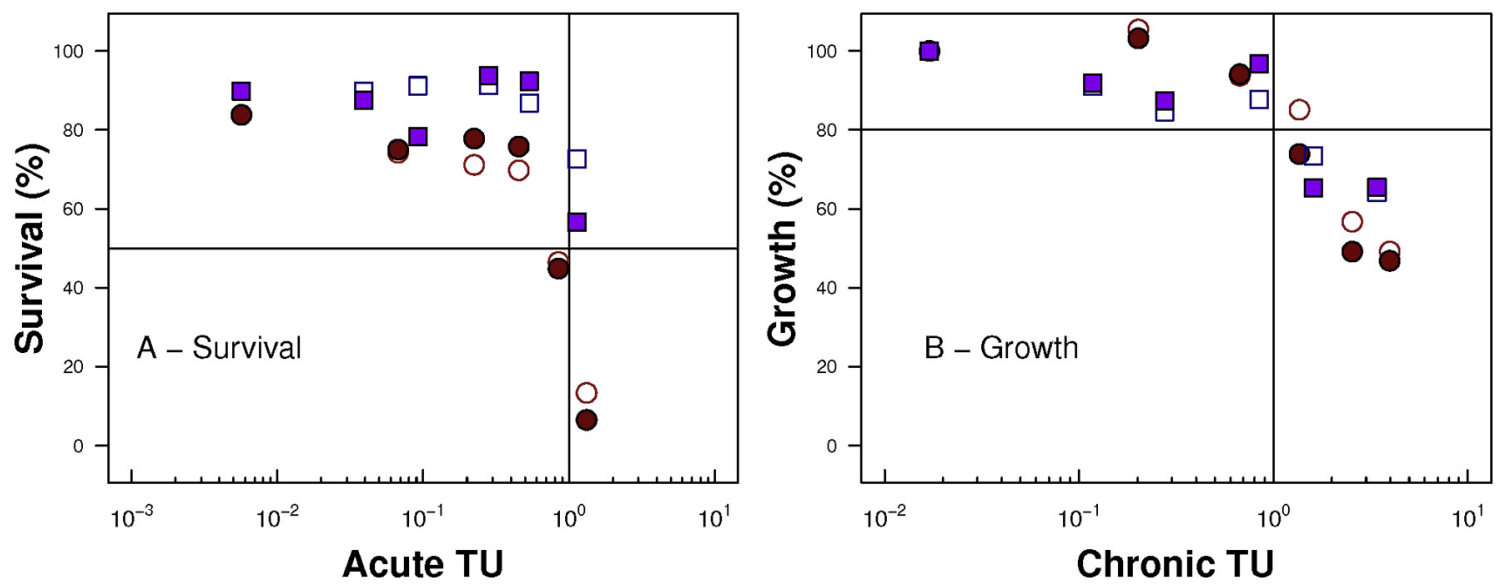

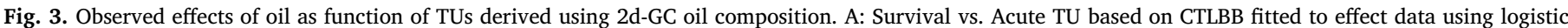

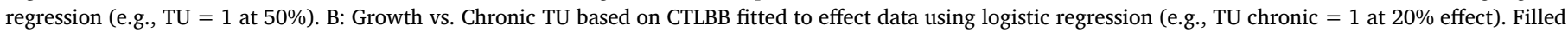

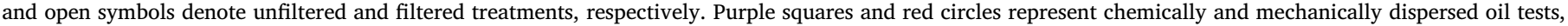
respectively. (For interpretation of the references to color in this figure legend, the reader is referred to the web version of this article.)

embryo-larval tests with aromatic hydrocarbons (Butler et al., 2016). This procedure was repeated to estimate a CTLBB of $14 \mu \mathrm{mol} / \mathrm{g}$ octanol that corresponds to a $20 \%$ growth effect at a chronic $\mathrm{TU}=1$ as shown in Fig. 3B. This value is near the median sublethal/chronic CTLBBs (reported range from 0.4 to $137 \mu \mathrm{mol} / \mathrm{g}$ octanol, $\mathrm{N}=36$ species) that have been derived using the TLM (McGrath et al., 2018). It should be noted that since modeling estimates may understate dissolved phase exposures that occurs as a result of loss processes in dispersed test exposures (see previous section), the resulting CTLBBs for cod larvae derived in this analysis are likely biased low and are thus conservative.

\subsection{Comparing predicted TUs for whole oil versus total PAH}

Simulated dissolved exposures were used to compute TUs associated with the PAHs targeted in this study for quantifying oil exposures. These calculations are summarized in Table 1 and indicate that the 44 PAHs considered only comprise 3 to $11 \%$ of the TUs associated with the whole oil; a reflection of the high naphthenic content of this oil. Further, this percentage changes with oil loading such that at low loadings, PAHs contribute less than the unresolved dissolved oil components. TUs were also computed using measured filtered concentrations of PAHs as summarized by calculations provided in Tables S3 and S4. For the three highest oil loadings from both MD and CD treatments, predicted dissolved TUs derived are in excellent agreement (less than a factor two different) from the TUs obtained directly using filtered PAH analyses. These results confirm the reliability of the oil solubility model that has been applied for estimating dissolved PAH exposures. For the two lowest oil loadings, modeled dissolved TUs are higher than obtained using filtered PAH measurements. The lower TUs derived from measured analyses likely reflect the confounding influence of analytical detection and test substance losses at oil loadings at or below $50 \mu \mathrm{g} / \mathrm{L}$.

These results highlight the challenges of using a limited suite of PAH analytes as an exposure metric for expressing toxicity data since such measurements only capture a fraction of the oil components that are expected to contribute to the observed toxicity. In addition, the fractional contribution of TUs associated with PAHs changes in a non-linear manner with oil loading and dosing method using the same test oil (Table 1). It is important to emphasize that since the concentration of individual PAHs varies widely across different crude oils (and weathering states) and given different investigators often quantitate an inconsistent target list of individual PAHs to characterize oil toxicity test exposures, the ratio of TUs associated with measured PAHs to unresolved dissolved oil components is expected to diverge across oil toxicity studies. This conclusion is supported by the recent modeling analysis provided by McConville et al. (2018) who investigated the acute toxicity of chemically dispersed Alaska North Slope Oil to sablefish. These investigators found that a suite of 38 individual PAHs used to quantify total PAH exposures in CEWAF treatments represented $20 \%$ of $\Sigma$ TUs that were predicted based on 2d-GC analysis of the test oil. The higher percentage reported compared to our findings using Troll Oil underscores the limitations of expressing and comparing oil toxicity data using traditional exposure metrics that only partially characterize both the concentration and composition of dissolved oil exposures (Redman and Parkerton, 2015). The practical implication of this work is that expressing oil toxicity data in terms of total PAH can yield misleading conclusions. Using total PAHs as the basis for interpreting toxicity test results in this study, it may be concluded that MD is more toxic than the CD test oil (Table 3). However, when expressed in terms of predicted TUs for the whole oil, MD and $\mathrm{CD}$ oil exhibit comparable toxicity (Fig. 3A).

Another important insight obtained from the modeling approach used in this study is the importance of different unresolved hydrocarbon classes in contributing to predicted effects. Fig. 4 summarizes the percent contribution of $2 \mathrm{~d}-\mathrm{GC}$ classes at the predicted total oil concentration $(=0.66 \mathrm{mg} / \mathrm{L})$ in which dissolved Troll Oil exposures yield an acute $\Sigma \mathrm{TU}=1$ (i.e., corresponding to a $50 \%$ effect on cod larval survival). Unresolved di- and polyaromatic hydrocarbons make up about $40 \%$ of the predicted TUs which implies that the target list of PAHs quantified by GC-MS analysis in this study captures less than a quarter of the unresolved constituents in these structural classes. Further monoaromatic and partially saturated cyclic structures containing one or two diaromatic rings (i.e. naphthenic aromatics) contribute more than half the predicted TUs. The important role of naphthenic aromatics on predicted toxicity reflects the high naphthenic content of Troll Oil. Linear and branched alkanes and mono, di and poly naphthenic classes are constrained by aqueous solubility and collectively represent $<5 \%$ of the predicted TUs. Thus, in the case of this test oil, aromatic containing hydrocarbon classes comprise over $95 \%$ of the acute TUs.

In past oil toxicity studies involving a specific oil or dosing method, the importance of unresolved oil components is not obvious since the total PAH metric commonly used to characterize oil exposures correlates to TUs associated with the dissolved components of the whole oil. Thus, the apparent dose-response relationship with observed effects can be misinterpreted as causation rather than correlation. This analysis highlights how 2d-GC analysis and CTLBB estimates for a given organism/endpoint can be used to evaluate how oils with different composition influences expected toxicity and the role various 


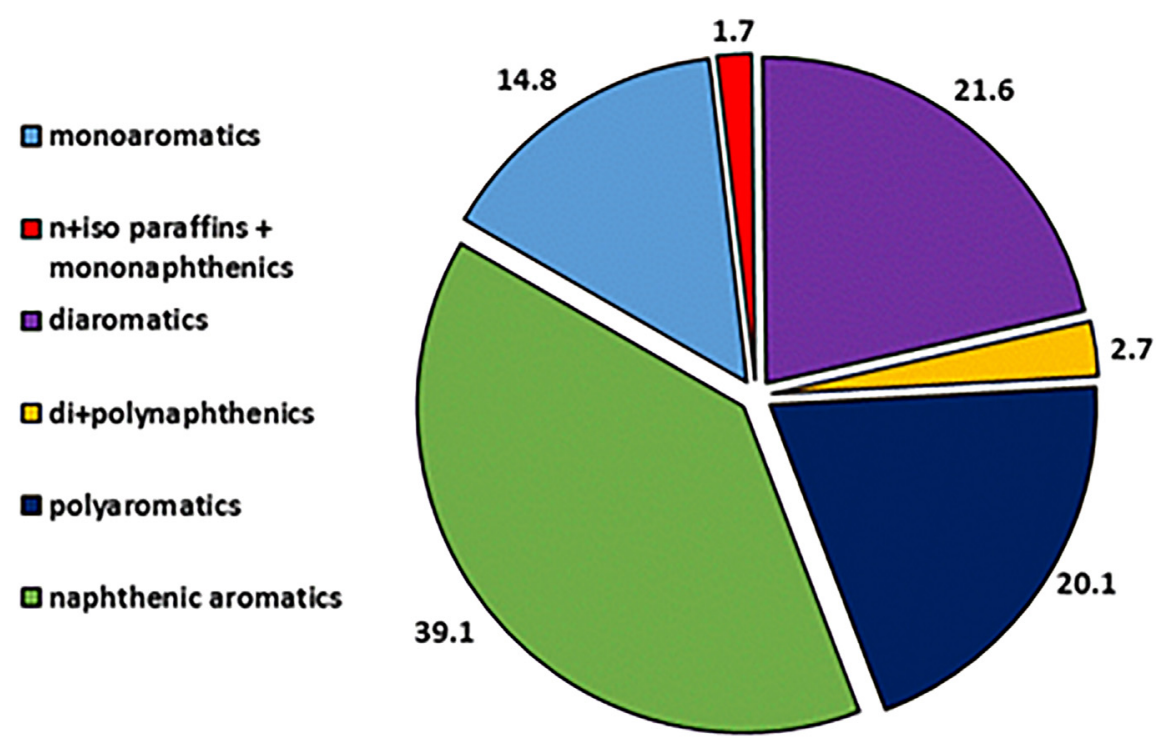

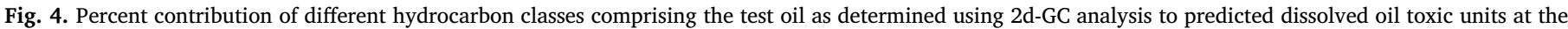
lethal loading.

constituents serve in contributing to these effects.

\section{Summary and recommendations}

A modeling framework was applied to PAH analytical measurements to deduce associated oil loadings for simulating dissolved and droplet oil exposures in marine oil toxicity tests with cod larvae. Observed effects on larval survival and growth were found to be successfully described using dissolved phase TUs in both treatments with and without droplet oil. These results highlight the limited role oil droplets served in contributing to toxicity. The estimated acute and chronic CTLBBs derived in this analysis indicates a similar sensitivity of this deep sea species to oil as compared to other pelagic species previously investigated (McGrath et al., 2018). Total PAHs were found to account for $10 \%$ or less of the predicted TUs for the artificially weathered naphthenic oil investigated with unresolved aromatic and naphthenic aromatic components contributing the majority of TUs (McGrath et al., 2018).

This study also highlights the limitations of using total PAH measurements as a general exposure metric in oil toxicity studies since dissolved versus droplet oil phases are not differentiated and different oils will contain varying PAH concentrations that upon dissolution will contribute in uncertain proportions and vary as a function of oil loading. Thus, the current practice for expressing oil toxicity test exposures limits the comparability between studies and the extrapolation of effects data across different oils. Furthermore, the use of such exposure metrics can lead to erroneous conclusions even within a given study.

The modeling framework described can be applied to other existing or future data sets (with different species and acute or chronic endpoints) to provide a comprehensive characterization of dissolved oil exposures and associated TUs. In future oil toxicity studies, direct measurements of oil droplet concentrations are recommended to independently confirm modeled estimates derived using the framework applied in this study. Additional considerations that would benefit future research include: 1 ). toxicity tests on individual hydrocarbons for the same organism/endpoint that is to be investigated for test oils so that a CTLBB defining the species/endpoint sensitivity can be directly determined (or confirmed, in the case of the estimates derived from this study for Atlantic cod larvae) using the TLM; and 2). passive sampling methods that provide a more complete characterization of dissolved oil exposures and thereby serves as a complimentary measure that correlates to modeled TUs and observed toxicity in oil contaminated media (Redman et al., 2018). Broader adoption of this strategy will foster improved insights regarding relative sensitivity of different organisms/endpoints and influence of oil composition on observed effects as well as inform more consistent design, analysis and interpretation of oil toxicity studies.

\section{Acknowledgements}

The experimental work used as a basis for the modeling was provided by the Research Council of Norway (Projects 184716/S40 and 196604/S40). The preparation of this manuscript was partially funded by the American Petroleum Institute (API Contract No.: 2015-110108).

\section{Appendix A. Supplementary data}

Supplementary data to this article can be found online at https:// doi.org/10.1016/j.marpolbul.2018.10.065.

\section{References}

Butler, J.D., Parkerton, T.F., Redman, A.D., Letinski, D.J., Cooper, K.R., 2016. Assessing aromatic-hydrocarbon toxicity to fish early life stages using passive-dosing methods and target-lipid and chemical-activity models. Environ. Sci. Technol. 50, 8305-8315.

Carls, M.G., Holland, L., Larsen, M., Collier, T.K., Scholz, N.L., Incardona, J.P., 2008. Fish embryos are damaged by dissolved PAHs, not oil particles. Aquat. Toxicol. 88, 121-127.

Couillard, C.M., Lee, K., Legare, B., King, T.L., 2005. Effect of dispersant on the composition of the water-accommodated fraction of crude oil and its toxicity to larval marine fish. Environ. Toxicol. Chem. 24, 1496-1504.

DeLeo, D.M., Ruiz-Ramos, D.V., Baums, I.B., Cordes, E.E., 2016. Response of deep-water corals to oil and chemical dispersant exposure. Deep-Sea Res. II Top. Stud. Oceanogr. 129, 137-147.

Froese, R., Pauly, D., 2017. FishBase. World Wide Web electronic publication.

Gardiner, W.W., Word, J.Q., Word, J.D., Perkins, R.A., McFarlin, K.M., Hester, B.W., Word, L.S., Ray, C.M., 2013. The acute toxicity of chemically and physically dispersed crude oil to key arctic species under arctic conditions during the open water season. Environ. Toxicol. Chem. 32, 2284-2300.

Hansen, B.H., Altin, D., Bonaunet, K., Øverjordet, I.B., 2014. Acute toxicity of eight oil spill response chemicals to temperate, boreal and Arctic species. J. Toxic. Environ. Health A 77, 495-505.

Hansen, B.H., Lie, K.K., Størseth, T.R., Nordtug, T., Altin, D., Olsvik, P.A., 2016. Exposure of first-feeding cod larvae to dispersed crude oil results in similar transcriptional and metabolic responses as food deprivation. J. Toxic. Environ. Health A 79, 558-571.

Johansen, Ø., Brandvik, P.J., Farooq, U., 2013. Droplet breakup in subsea oil releases-part 2: predictions of droplet size distributions with and without injection of chemical dispersants. Mar. Pollut. Bull. 73, 327-335.

John, V., Arnosti, C., Field, J., Kujawinski, E., McCormick, A., 2016. The Role of 
Dispersants in Oil Spill Remediation: Fundamental Concepts, Rationale for Use, Fate, and Transport Issues.

Kang, H.-J., Lee, S.-Y., Roh, J.-Y., Yim, U.H., Shim, W.J., Kwon, J.-H., 2014. Prediction of ecotoxicity of heavy crude oil: contribution of measured components. Environ. Sci. Technol. 48, 2962-2970.

Khan, R., Payne, J., 2005. Influence of a crude oil dispersant, Corexit 9527, and dispersed oil on capelin (Mallotus villosus), Atlantic cod (Gadus morhua), longhorn sculpin (Myoxocephalus octodecemspinosus), and cunner (Tautogolabrus adspersus). Bull. Environ. Contam. Toxicol. 75, 50-56.

Klok, C., Nordtug, T., Tamis, J.E., 2014. Estimating the impact of petroleum substances on survival in early life stages of cod (Gadus morhua) using the Dynamic Energy Budget theory. Mar. Environ. Res. 101, 60-68.

McConville, M.M., Roberts, J.P., Boulais, M., Woodall, B., Butler, J.D., Redman, A.D., Parkerton, T.F., Arnold, W.R., Guyomarch, J., LeFloch, S., 2018. The sensitivity of a deep-sea fish species (Anoplopoma fimbria) to oil-associated aromatic compounds, dispersant, and Alaskan North Slope crude oil. Environ. Toxicol. Chem. 37, $2210-2221$.

McGrath, J.A., Di Toro, D.M., 2009. Validation of the target lipid model for toxicity assessment of residual petroleum constituents: monocyclic and polycyclic aromatic hydrocarbons. Environ. Toxicol. Chem. 28, 1130-1148.

McGrath, J.A., Fanelli, C.J., Toro, D.M., Parkerton, T.F., Redman, A.D., Paumen, M.L., Comber, M., Eadsforth, C.V., Haan, K., 2018. Re-evaluation of target lipid modelderived HC5 predictions for hydrocarbons. Environ. Toxicol. Chem. 37, 1579-1593.

Mu, J., Jin, F., Ma, X., Lin, Z., Wang, J., 2014. Comparative effects of biological and chemical dispersants on the bioavailability and toxicity of crude oil to early life stages of marine medaka (Oryzias melastigma). Environ. Toxicol. Chem. 33, 2576-2583.

Murphy, D., Gemmell, B., Vaccari, L., Li, C., Bacosa, H., Evans, M., Gemmell, C., Harvey, T., Jalali, M., Niepa, T.H., 2016. An in-depth survey of the oil spill literature since 1968: long term trends and changes since Deepwater Horizon. Mar. Pollut. Bull. 113, 371-379.

Nordtug, T., Olsen, A.J., Altin, D., Meier, S., Overrein, I., Hansen, B.H., Johansen, Ø., 2011a. Method for generating parameterized ecotoxicity data of dispersed oil for use in environmental modelling. Mar. Pollut. Bull. 62, 2106-2113.

Nordtug, T., Olsen, A.J., Altin, D., Overrein, I., Storøy, W., Hansen, B.H., De Laender, F., 2011b. Oil droplets do not affect assimilation and survival probability of first feeding larvae of North-East Arctic cod. Sci. Total Environ. 412, 148-153.

NRC, 2005. Oil Spill Dispersants: Efficacy and Effects. The National Academies Press, Washington D.C.

Olsvik, P.A., Nordtug, T., Altin, D., Lie, K.K., Overrein, I., Hansen, B.H., 2010. Transcriptional effects on glutathione S-transferases in first feeding Atlantic cod (Gadus morhua) larvae exposed to crude oil. Chemosphere 79, 905-913.

Olsvik, P.A., Hansen, B.H., Nordtug, T., Moren, M., Nolen, E., Lie, K.K., 2011. Transcriptional evidence for low contribution of oil droplets to acute toxicity from dispersed oil in first feeding Atlantic cod (Gadus morhua) larvae. Comp. Biochem. Physiol. C-toxicol. Pharmacol. 154, 333-345.

Olsvik, P.A., Lie, K.K., Nordtug, T., Hansen, B.H., 2012. Is chemically dispersed oil more toxic to Atlantic cod (Gadus morhua) larvae than mechanically dispersed oil? A transcriptional evaluation. BMC Genomics 13.

Ottera, H., 2004. Cultured aquatic species information programme. In: Gadhus morhua. FAO Fishers and Aquaculture Department, Rome (online).

Prince, R.C., 2015. Oil spill dispersants: boon or bane? Environ. Sci. Technol. 49, 6376-6384.

Ramachandran, S.D., Hodson, P.V., Khan, C.W., Lee, K., 2004. Oil dispersant increases PAH uptake by fish exposed to crude oil. Ecotoxicol. Environ. Saf. 59, 300-308.

Redman, A., 2015. Role of entrained droplet oil on the bioavailability of petroleum substances in aqueous exposures. Mar. Pollut. Bull. 97, 342-348.

Redman, A.D., Parkerton, T.F., 2015. Guidance for improving comparability and relevance of oil toxicity tests. Mar. Pollut. Bull. 98, 156-170.

Redman, A.D., McGrath, J.A., Stubblefield, W.A., Maki, A.W., Di Toro, D.M., 2012a. Quantifying the concentration of crude oil microdroplets in oil-water preparations. Environ. Toxicol. Chem. 31, 1814-1822.

Redman, A.D., Parkerton, T.F., McGrath, J.A., Di Toro, D.M., 2012b. PETROTOX: an aquatic toxicity model for petroleum substances. Environ. Toxicol. Chem. 31, 2498-2506.

Redman, A.D., Parkerton, T.F., Letinski, D.J., Manning, R.G., Adams, J.E., Hodson, P.V., 2014. Evaluating toxicity of heavy fuel oil fractions using complementary modeling and biomimetic extraction methods. Environ. Toxicol. Chem. 33, 2094-2104.

Redman, A.D., Butler, J.D., Letinski, D.J., Parkerton, T.F., 2016. Investigating the role of dissolved and droplet oil in aquatic toxicity using dispersed and passive dosing systems. Environ. Toxicol. Chem. 36, 1020-1028.

Redman, A., Butler, J., Letinski, D., Di Toro, D., Paumen, M.L., Parkerton, T., 2018. Technical basis for using passive sampling as a biomimetic extraction procedure to assess bioavailability and predict toxicity of petroleum substances. Chemosphere 199, 585-594.

Rose, G.A., Rowe, S., 2015. Northern cod comeback. Can. J. Fish. Aquat. Sci. 72, $1789-1798$.

Schein, A., Scott, J.A., Mos, L., Hodson, P.V., 2009. Oil dispersion increases the apparent bioavailability and toxicity of diesel to rainbow trout (Oncorhynchus mykiss). Environ. Toxicol. Chem. 28, 595-602.

Sobel, J., 1996. Gadus morhua. The IUCN Red List of Threatened Species 1996: e.T8784A12931575.

Stiver, W., Mackay, D., 1984. Evaporation rate of spills of hydrocarbons and petroleum mixtures. Environ. Sci. Technol. 18, 834-840.

Van Scoy, A.R., Anderson, B.S., Philips, B.M., Voorhees, J., McCann, M., De Haro, H., Martin, M.J., McCall, J., Todd, C.R., Crane, D., Sowby, M.L., Tjeerdema, R.S., 2012. NMR-based characterization of the acute metabolic effects of weathered crude and dispersed oil in spawning topsmelt and their embryos. Ecotoxicol. Environ. Saf. 78, 99-109.

Wu, D.M., Wang, Z.D., Hollebone, B., McIntosh, S., King, T., Hodson, P.V., 2012. Comparative toxicity of four chemically dispersed and undispersed crude oils to rainbow trout embryos. Environ. Toxicol. Chem. 31, 754-765. 